\title{
Dinâmica da decomposição dos adubos verdes na manutenção da fertilidade do solo, disponibilidade de nutrientes e manejo agroecológico de plantas espontâneas em hortaliças
}

Raimundo Nonato Viana Santos, Maycon Pedrosa Cardoso, Caio Vinicius Sales Pereira Da Macena, Luciana Lins Oliveira Santos, Maria Rosângela Malheiros Silva

https://doi.org/10.4322/mp.978-65-991393-9-0.c5

\section{Resumo}

A pesquisa objetivou avaliar a taxa de decomposição de adubos verdes em cultivo de quiabeiro para disponibilização de nutrientes e redução da entrada de insumos externos para os agricultores. O experimento foi conduzido em área da UEMA, São Luís/MA em blocos casualizados com quatro repetições, em esquema fatorial: adubos verdes, sistema de cultivo (consorciado e monocultivo) e épocas de decomposição dos resíduos (10, 20, 30, 40, 50 dias). Para avaliar a dinâmica de decomposição dos resíduos, foram colocadas $100 \mathrm{~g}$ de massa fresca dos adubos verdes dentro de litter bags sobre a superfície do solo. O feijão caupi em monocultivo e consorciado apresentou o menor tempo de meia vida, 32 e 29 dias, respectivamente e o feijão manteguinha o maior tempo de meia vida, 58 dias. A biomassa das leguminosas apresenta uma decomposição inicial rápida, seguida de outra mais lenta. O feijão manteiguinha apresenta maior massa seca remanescente e tempo de meia vida.

Palavras-chave: avaliação, biomassa, leguminosa, massa remanescente. 


\section{Introdução}

A adubação verde é uma pratica agrícola que inicialmente objetivava a conservação do solo, com relatos do seu uso desde a Era Cristã para recuperar solos degradados, melhorar os solos naturalmente pobres e conservar aqueles produtivos. Porém, com o auge da Revolução Verde essa prática que antes tinha importante função foi temporariamente deixada de lado e substituída pelos chamados fertilizantes sintéticos, que apresentavam rápida resposta pelas culturas após a sua aplicação no solo [1].

A adubação verde pode ser definida com uma prática agrícola que usa espécies vegetais em rotação ou em consórcio com culturas de interesse econômico. Essas espécies podem ser de ciclo anual ou perene, cobrem o terreno por determinado período de tempo ou durante todo o ano [2].

A adubação verde tem sido utilizada como alternativa prática e eficaz para o fornecimento de nutrientes e a adição de matéria orgânica ao solo, diretamente, na área de cultivo [3]. As características agronômicas e fenológicas permitem que os adubos verdes sejam cultivados de muitas maneiras nos mais diversos tipos de arranjos e configurações, para viabilizar o uso e o manejo sustentável do solo e a produção de alimentos de qualidade [1].

Uma das modalidades de manejo da adubação verde no cultivo de hortaliças é o consórcio que favorece o melhor aproveitamento do espaço físico, do controle de fitopatógenos do solo e das plantas espontâneas para os agricultores familiares. Segundo Fontanétti et al. [4], elas geralmente formam uma barreira física para as plantas espontâneas que competem por recursos do meio ambiente e, quando manejadas adequadamente, podem diminuir as capinas manuais e evitar a utilização de herbicidas.

A adubação verde proporciona inúmeras vantagens ao cultivo de hortaliças, colocar as vantagens citada por Tivelli et al. [5] também menciona que a principal vantagem imediata com uso de adubos verdes a exemplo das crotalárias é o controle de plantas espontâneas nas entrelinhas da cultura, adição de nitrogênio ao solo, ciclagem dos nutrientes que estão em maior profundidade e redução da população de nematóides no solo. Além de favorecem a manutenção da matéria orgânica do solo, o sequestro de carbono da atmosfera e a recuperação dos solos degradados. 
Os adubos verdes também servem com proteção do solo e disponibilizam nutrientes que reduzem a entrada de insumos externos. Kliemann et al. [6] destacaram que a taxa de decomposição do resíduo vegetal a ser utilizado como cobertura é um fator fundamental para determinar o tempo de permanência da cobertura morta na superfície do solo. Quanto mais rápida for a sua decomposição, maior será a velocidade de liberação de nutrientes, entretanto diminuem a proteção do solo.

A escolha da espécie adequada para adubação verde está relacionada com as características de cada região, como o clima e solo. Cada espécie vegetal apresenta exigências específicas com relação à fertilidade do solo e quanto ao clima. Como consequência, torna-se importante fazer a escolha das plantas mais adequadas ao uso de adubos verdes, a partir das condições edafoclimáticas observadas em cada região [7]. Assim, o objetivo desse trabalho foi avaliar a taxa de decomposição de diferentes adubos verdes em cultivo de quiabeiro para disponibilização de nutrientes e redução da entrada de insumos externos para os agricultores.

\section{Materiais e Métodos}

O experimento foi conduzido em área da Fazenda Escola da Universidade Estadual do Maranhão em São Luís - MA no período de abril a junho de 2017, localizado a Latitude S $2^{\circ} 31^{\prime}$ e Longitude W 44 $16^{\prime}$. O clima local segundo a classificação de Köppen é do tipo Aw', ou seja, equatorial quente e úmido, com estação chuvosa de janeiro a junho (média de 2010 mm) e estação seca de julho a dezembro (média de $180 \mathrm{~mm}$ ), com temperatura média anual de $26,1^{\circ} \mathrm{C}$, com variações de $30,4^{\circ} \mathrm{C}$ a $23,3^{\circ} \mathrm{C}$ e umidade relativa média de $88 \%$ [8].

O experimento foi instalado em blocos casualizados com quatro repetições, em esquema fatorial com três fatores: adubos verdes (crotalária, feijão caupi BRS Guariba, mucuna-cinza, feijão caupi Manteguinha), sistema de cultivo (consorciado e monocultivo) e épocas de avaliação da decomposição dos resíduos (10, 20, 30, 40 e 50 dias após implantação no campo - DAl). Além de duas testemunhas, sem adubação verde com capina e sem capina com vegetação espontânea. As parcelas experimentais do quiabeiro em consórcio com os adubos verdes foram constituídas por quatro linhas de 3,20 $\mathrm{m}$ de 
comprimento espaçadas de 1,0 m entre linhas de plantio e 0,40 m entre plantas, totalizando 64 plantas de quiabo por parcela.

Como área útil foi considerada as duas linhas centrais e de bordaduras as linhas laterais. Aos oito dias após o transplantio da cultura (DAT) foi realizada uma roçagem para a semeadura dos adubos verdes nas entrelinhas do quiabeiro e nas parcelas do monocultivo.

No consórcio foram semeadas duas linhas de cada adubo verde nas entrelinhas do quiabeiro. Para avaliar a dinâmica de decomposição dos resíduos foram colocadas amostras com $100 \mathrm{~g}$ de matéria fresca de todos os tipos de adubos verdes as quais foram colocadas dentro de litter bags, bolsas confeccionadas com tela plástica, com abertura de malha de $5 \mathrm{~mm}$, que permitem a colonização por microrganismos e alguns invertebrados.

Para determinação do peso seco inicial (tempo zero), foram pesadas cinco amostras de $100 \mathrm{~g}$ de material fresco, que foi seco em estufa a $65^{\circ} \mathrm{C}$ por 72 horas. Os litter bags foram distribuídos sobre a superfície do solo nas parcelas de origem no campo, sendo as taxas de perda de matéria seca monitorada através de coletas realizadas aos 10, 20, 30, 40 e 50 dias após a colocação dos litter bags no campo.

Para medir a taxa de decomposição utilizou-se o modelo exponencial simples utilizado por Rezende et al. [9], em que $\mathrm{k}$ expressa a taxa de decomposição dos resíduos e liberação de nutrientes. Para equacionar o tempo de $1 / 2$ vida utilizou-se a seguinte fórmula $t 1 / 2=\ln (2) / k$, onde $t \frac{1}{2}$ é 0 tempo de meia vida da matéria seca, ou seja, corresponde ao número de dias em que os adubos verdes gastaram para decompor $50 \%$ da sua biomassa.

\section{Resultados e Discussão}

Os adubos verdes apresentaram a mesma tendência no processo de decomposição da biomassa mantida nos litters bags, apresentando uma fase inicial rápida até aos 30 dias, seguida de outra fase mais lenta (Figura 1).

O feijão manteguinha apresentou os maiores valores de massa seca remanescente, enquanto o consórcio feijão caupi mais quiabeiro obtiveram menores valores. Esse resultado sugere que o feijão caupi fornece para a cultura nutrientes em sua fase inicial, já o feijão manteiguinha protege o solo por mais tempo. Osório et al. [10] em pesquisas com decomposição de adubos 
verdes consorciado com bananeira também observou essa cinética na decomposição.

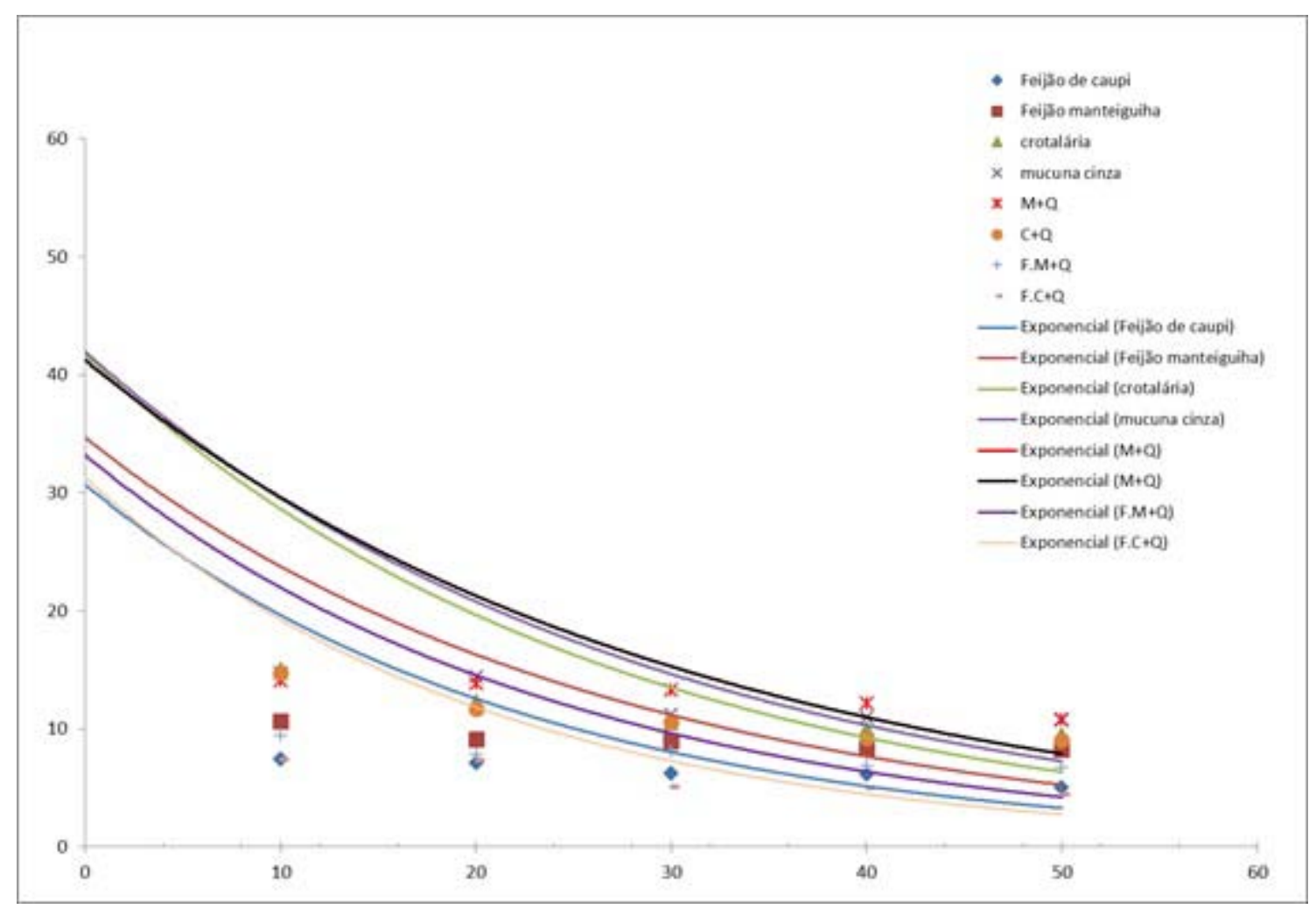

Figura 1. Percentual de massa seca decomposta dos adubos verdes para cada tempo de coleta após a colocação dos litter bags no campo. São Luís-MA, 2017.

Outra característica importante para a avaliação da decomposição dos adubos verdes é o tempo de meia-vida (T1/2), que representa o período de tempo necessário para que metade dos resíduos se decomponha, e a constante de decomposição (K) (tabela 1). Para hortaliças que tem ciclo de produção curto é fundamental entender como os adubos verdes podem interagir com elas. A presença do material após o corte servirá de base de nutrientes para a cultura sucessora e barreira física ao surgimento de plantas espontâneas. Dessa forma, a ideia é combinar diferentes adubos verdes que possam fornecer essas características desejáveis no agroecossistema de cultivo. 
Tabela 1. Equações de decomposição, Taxa de decomposição (k), Tempo de meia vida (t1/2) em dias e coeficiente de determinação $\left(r^{2}\right)$ para decomposição de massa seca dos adubos verdes avaliados. São Luís- MA, 2017.

\begin{tabular}{|lllll|}
\hline & \multicolumn{1}{c}{ Equação } & \multicolumn{1}{c}{$R^{2}$} & $T 1 / 2$ & \multicolumn{1}{c|}{$K$} \\
\hline Feijão caupi & $Y=90,234 e^{-0,176 x}$ & $R 2=0,7594$ & 32 & $\mathbf{- 0 , 0 2 1 9 4}$ \\
Feijão manteiguinha & $Y=94,964 e^{-0,107 x}$ & $R 2=0,771$ & 58 & $-\mathbf{0 , 0 1 1 9 3}$ \\
Crotalária & $y=102,17 e^{-0,154 x}$ & $R^{2}=0,8937$ & 43 & $\mathbf{- 0 , 0 1 5 9 3}$ \\
mucuna cinza & $y=94,03 e^{-0,15 x}$ & $R^{2}=0,7855$ & 40 & $-\mathbf{0 , 0 1 7 2}$ \\
Mucuna cinza+Quiabeiro & $y=90,581 e^{-0,135 x}$ & $R^{2}=0,7279$ & 41 & $\mathbf{- 0 , 0 1 7 0 3}$ \\
Crotalaria+Quiabeiro & $y=102,34 e^{-0,164 x}$ & $R^{2}=0,8982$ & 41 & $\mathbf{- 0 , 0 1 6 9 7}$ \\
F. Manteguinha+Quiabeiro & $y=94,246 e^{-0,142 x}$ & $R^{2}=0,7874$ & 43 & $\mathbf{- 0 , 0 1 6 1 9}$ \\
F.Caupi+Quiabeiro & $y=77,132 e^{-0,022 x}$ & $R^{2}=0,8303$ & 29 & $\mathbf{- 0 , 0 2 4 1 6}$ \\
\hline
\end{tabular}

O feijão caupi em monocultivo e consorciado apresentaram os menores tempo de meia vida, 32 e 29 dias respectivamente, precisando de um tempo de 64 e 48 dias para decompor por completo o feijão caupi em monocultivo e consorciado com quiabeiro. Portanto, o tempo de permanência dos resíduos vegetais sobre o solo é fundamental na tomada de decisão sobre qual manejo e composição de adubos verdes adotar [11]. Quando observado o período crítico de interferência das plantas espontâneas na cultura do quiabeiro que varia de 12 a 36 dias após a emergência na estação chuvosa Santos et al., [12], e de quatro a 53 dias após o transplantio na estação seca Santos et al., [13] infere-se que os adubos verdes depositados no solo podem ser uma alternativa eficientes a curto e médio prazo no manejo das plantas espontâneas.

A mucuna cinza e a crotalária consociadas apresentaram um tempo de 41 dias para que metade de sua fitomassa fosse perdida. O feijão manteguinha foi o adubo que apresentou maior tempo de meia vida com 58 dias para decompor $50 \%$ de seu material.

A decomposição depende de fatores ambientais locais e das características químicas de cada espécie vegetal, o que acarreta uma grande variabilidade nas taxas de decomposição [14]. 
Fatores como temperatura, umidade, aeração e teor de matéria orgânica no solo, atuarão principalmente na atividade microbiana, mensurando o processo de decomposição da biomassa das plantas [15]. Ainda há o rigor da insolação equatorial que acelera a decomposição e queima da matéria orgânica do solo, que, no trópico, é muito importante para neutralizar a acidez tóxica e manter a estrutura do solo por onde deve fluir o excesso de água [16].

É importante o estudo da decomposição de adubos verdes, na busca de ajustes para sua melhor utilização, principalmente em sistemas agroecológicos de produção, de modo a utilizar os benefícios da liberação dos nutrientes provenientes da decomposição. Oliveira et al. [17] relataram que os benefícios trazidos pelas coberturas mortas de leguminosas resultam, principalmente, da disponibilização de nitrogênio para a cultura, liberado através da acelerada decomposição dos resíduos. O consórcio quiabeiro com crotalária proporcionou aumento de até $13 \%$ da produção de frutos do quiabeiro, além de reduzir a incidência de galhas radiculares devidas a Meloidogyne spp. [18].

Além disso, para a utilização dos consórcios em regiões com temperaturas mais elevadas, é necessária a adaptação da tecnologia, por meio da identificação de combinações entre espécies mais adaptadas, além do entendimento da dinâmica de decomposição do material e da imobilização/mineralização de nutrientes no solo [19].

\section{Conclusão}

A biomassa das leguminosas apresenta uma decomposição inicial rápida e depois decompõe-se de forma mais lenta. O adubo verde com a maior massa seca remanescente é o feijão manteguinha que também apresenta o maior tempo de meia vida.

\section{Referências}

[1] Wildner L.P. Adubação verde: conceitos e modalidades de cultivo. In: Lima Filho O.F., Ambrosano E.J., Rossi F., Carlos J.A.D. (ed.) Adubação verde e plantas de cobertura no Brasil: fundamentos e prática. Embrapa; 2014, p. 1944. Brasília-DF, Brasil.

[2] Wutke E.B., Ambrosano E.J., Razera L.F., Medina P.F., Carvalho L.H., Kikuti $\mathrm{H}$. Bancos comunitários de sementes de adubos verdes: informações 
técnicas. Brasília: Ministério da Agricultura, Pecuária e Abastecimento, 2007. $52 \mathrm{p}$.

[3] Sediyama M.A.N., Santos I.C., Lima P.C. Cultivo de hortaliças no sistema orgânico. Revista Ceres, Viçosa 2014; 61: 829-837. https://doi.org/10.1590/0034-737x201461000008.

[4] Fontanétti A., Carvalho G.J. de., Morais A.R. de, Almeida K. de, Duarte W.F. Adubação verde no controle de plantas invasoras nas culturas de alface americana e de repolho. Ciência e Agrotecnologia 2004; 28(5): 967-973. https://doi.org/10.1590/S1413-70542004000500001.

[5] Tivelli S.W., Purqueiro L.F.V., Kano C. Adubação verde e plantio direto em hortaliças. Pesquisa \& Tecnologia 2010; 7(1)

[7] Espindola J.A.A., Guerra J.G.M., Almeida D.L. Uso de leguminosas herbáceas para adubação verde. In: Aquino A., Assis R.L. Agroecologia: princípios e técnicas para uma agricultura orgânica sustentável. Embrapa; 2005, p. 435-451. Brasília: Brasil.

[8] Instituto Nacional de Meteorologia. Normas climatológicas do Brasil 19611990. Brasília, DF. 2009. 465p.

[9] Rezende C. de P., Cantarutti R. B., Braga J. M., Gomide J. A., Pereira J. M., Ferreira E., Tarré R., Macedo R., Alves B.J.R., Urquiaga S., Cadisch G., Giller K.E., Boddey R.M. Litter deposition and disappearance in Brachiaria pastures in the Atlantic Forest region of South of Bahia, Brazil. Nutrient Cycling in Agroecosystems 1999, 54(2): 99- 112.

[10] Osório C.R.W. de S., Carneiro L.F., Souza E.I.S., Souza H.M., Padovan P. S., Salomão G. de B., Padovan M.P. Decomposição de adubos verdes perenes consorciados com a bananeira em um sistema sob transição agroecológica em Mato Grosso do Sul. Cadernos de Agroecologia, [S.I.] 2012; 7(2). Disponível em: <http://revistas.aba agroecologia.org.br/index.php/cad/article/view/13092>. Acesso em: 03 june 2019.

[11] Rafael M.R.S., Salviano A.M., Lima A.M.N., Cunha J.C., Silva P.G., Giongo V. Decomposição de adubos verdes em condições semi-áridas irrigadas. Anais da III jornada de pós-graduaçâo da embrapa semi-árido. 2018.

[12] Santos R.N.V., Rodrigues A.A.C., Silva M.R.M., Correa M.J.P., Mesquita M.L.R. Phytosociology and weed interference in okra under organic cropping 
system. African Journal of Agricultural Research 2017; 12(4): 251-259. https://doi.org/10.5897/AJAR2016.11888.

[13] Santos R.N.V., Pires T.P., Mesquita M.L.R., Correa M.J.P., Silva M.R.M. Weed interference in okra crop in the organic system during the dry season. Planta Daninha 2020; 38(2). https://doi.org/10.1590/s0100-83582020380100014.

[14] Gomes T.C. de A., Silva M.S.L. da, Silva J.A.M., Carvalho N.C.S. de, Soares E.M.B. Padrão de decomposição e liberação de nutrientes de adubos verdes em cultivos de uva e manga do Submédio São Francisco. Boletim de Pesquisa e Desenvolvimento, n. 71. Petrolina, Embrapa Semi-Árido. 2005. 24 p.

[15] Aita C., Giacomini S.J. Decomposição e liberação de nitrogênio de resíduos culturais de plantas de cobertura de solo solteiras e consorciadas. Revista Brasileira de Ciência do Solo, Viçosa 2003; 27:601-612. https://doi.org/10.1590/S0100-06832003000400004.

[16] Moura E.G. Agroambientes de transição: entre o trópico úmido e semiárido maranhense. $1^{\mathrm{a}} \mathrm{ed}$. 2004. 300p.

[17] Oliveira F.F de, Guerra J.G.M., Almeida D.L de, Ribeiro R. de L.D., Espindola J.A.A, Ricci M. dos S.F., Ceddia M.B. Avaliação de coberturas mortas em cultura de alface sob manejo orgânico. Horticultura Brasileira 2008; 26: $216-220$.

[18] Ribas R.G.T., Junqueira R.M., Oliveira F.L., Guerra J.G.M., Almeida D.L., Alves B.J.R., Ribeiro R.L.D. Desempenho do quiabeiro (Abelmoschus esculentus) consorciado com Crotalaria juncea sob manejo orgânico. Agronomia 2003; 37(2): 80 - 84.

[19] Teixeira C.M., Carvalho G.J. de, Andrade M.J.B.A. de, Silva C.A., Pereira J.M. Decomposição e liberação de nutrientes das palhadas de milheto e milheto + crotalária no plantio direto do feijoeiro. Acta Scientiarum. Agronomy 2009; 31: 647-653. https://doi.org/10.1590/S1807-86212009000400015. 


\section{Autores}

Raimundo Nonato Viana Santos*, Maycon Pedrosa Cardoso, Caio Vinicius Sales Pereira Da Macena, Luciana Lins Oliveira Santos, Maria Rosângela Malheiros Silva

Universidade Estadual do Maranhão, Cidade Universitaria Paulo VI, São Luís, Brasil.

* Autor para correspondência: rvianasantos@gmail.com 